\title{
Use of iliac crest allograft for Dega pelvic osteotomy in patients with cerebral palsy
}

Ki Hyuk Sung ${ }^{1 \dagger}$, Soon-Sun Kwon ${ }^{2 \dagger}$, Chin Youb Chung ${ }^{1}$, Kyoung Min Lee ${ }^{1}$, Jaeyoung Kim ${ }^{3}$ and Moon Seok Park ${ }^{*^{*}}$ (D)

\begin{abstract}
Background: Dega pelvic osteotomy is commonly performed procedure in patients with cerebral palsy (CP) undergoing hip reconstructive surgery for hip displacement. However, there has been no study investigating the outcomes after Dega pelvic osteotomy using allograft in patients with CP. This study investigated the outcomes of Dega pelvic osteotomy using iliac crest allograft in CP with hip displacement and the factors affecting allograft incorporation.

Methods: This study included 110 patients (150 hips; mean age 8y7mo; 68 males, 42 females) who underwent hip reconstructive surgeries including Dega pelvic osteotomy using iliac crest allograft. To evaluate the time of allograft incorporation, Goldberg score was evaluated according to the follow-up period on all postoperative hip radiographs. The acetabular index, migration percentage, and neck-shaft angle were also measured on the preoperative and postoperative follow-up radiographs.
\end{abstract}

Results: The mean estimated time for allograft incorporation (Goldberg score $\geq 6$ ) was 1.1 years postoperatively. All hips showed radiographic union at the final follow-up and there was no case of graft-related complications. Patients with Gross Motor Function Classification System (GMFCS) level V had 6.9 times higher risk of radiographic delayed union than those with GMFCS level III and IV. Acetabular index did not increase during the follow-up period $(p=0.316)$.

Conclusions: Dega pelvic osteotomy using iliac crest allograft was effective in correcting acetabular dysplasia, without graft-related complications in patients with CP. Furthermore, the correction of acetabular dysplasia remained stable during the follow-up period.

Keywords: Dega osteotomy, lliac crest allograft, Cerebral palsy, Goldberg score, Aceteabular dysplasia

\section{Background}

Cerebral palsy (CP) is defined as a group of permanent motor impairment disorders that are attributed to non-progressive disturbances in the brain of a developing fetus or infant. [1] Hip displacement (subluxation or dislocation) is common deformity in CP patients with severe impairment and is associated with acetabular dysplasia. [2] It can lead to pain and severe contractures, resulting in difficulties with perineal care, sitting balance, standing, and walking, as well as reduced quality of life. [3] Severely subluxated or dislocated hip can be

\footnotetext{
*Correspondence: pmsmed@gmail.com

${ }^{\dagger}$ Ki Hyuk Sung and Soon-Sun Kwon contributed equally to this work.

${ }^{1}$ Department of Orthopaedic Surgery, Seoul National University Bundang

Hospital, 82 Gumi-ro 173 Beon-gil, Bundang-Gu, Sungnam, Gyeonggi 13620,

South Korea

Full list of author information is available at the end of the article
}

corrected by hip reconstructive surgeries including proximal femoral varus osteotomy (FVO), either separately or in combination with several different types of pelvic osteotomy. [4] In patients with adequate sourcil and presence of a triradiate cartilage, reconstruction of the acetabulum using the Dega technique stabilizes the pelvis better than other techniques because it is a stable and incomplete osteotomy, and does not affect the medial cortex of the ilium. [5]

Most studies reported the use of iliac crest or femoral autograft as the interposition material for Dega osteotomy. The stability and the maintenance of osteotomy are dependent on the strength of the graft materials. [6] However, patients with $\mathrm{CP}$ have the osteoporotic features around the hip joint. [7] When an autogenous bone graft from the iliac crest is used, it may cause

(c) The Author(s). 2018 Open Access This article is distributed under the terms of the Creative Commons Attribution 4.0 International License (http://creativecommons.org/licenses/by/4.0/), which permits unrestricted use, distribution, and reproduction in any medium, provided you give appropriate credit to the original author(s) and the source, provide a link to the Creative Commons license, and indicate if changes were made. The Creative Commons Public Domain Dedication waiver (http://creativecommons.org/publicdomain/zero/1.0/) applies to the data made available in this article, unless otherwise stated. 
growth disturbances in the iliac bone due to splitting of the iliac apophysis, longer operation time, and increased blood loss. [8, 9] Therefore, our institution has been used iliac crest allograft as an interposition material for the Dega osteotomy in patients with CP.

Tricortical iliac allograft bone is widely available, has no donor site morbidity for harvesting, and has similar bone union rates as an autograft. $[10,11]$ Nevertheless, an allograft poses some concerns about the risk of transmission of infectious disease and graft rejection. [12, 13] However, a bone demineralization process can decrease the rates of disease transmission. [14] Several studies have reported allograft failure after operations on the spine, humerus, tibia and calcaneus. [15-19] However, to our knowledge, no study has investigated the outcomes after Dega pelvic osteotomy using allograft in patients with $\mathrm{CP}$.

In the present study, we aimed to investigate the outcomes after Dega pelvic osteotomy, using iliac crest allograft in patients with CP. Furthermore, we also investigated the factors influencing allograft incorporation.

\section{Methods}

\section{Participants}

The inclusion criteria were (1) consecutive children with $\mathrm{CP}$ with hip displacement (2) patients who underwent hip reconstructive surgeries, including Dega pelvic osteotomy and FVO from 2003 to 2015, (2) patients with a minimum follow-up of 1 year, and (3) patients who had preoperative and at least two postoperative follow-up hip radiographs. Patients with a history of hip surgery and with inappropriate hip radiographs for assessment were excluded.

\section{Surgical protocol}

At our hospital, hip reconstructive surgeries, including Dega pelvic osteotomy and FVO, were performed in displaced hips by two pediatric orthopedic surgeons. Hip reconstructive surgery was indicated in patients with a migration percentage (MP) of more than $33 \%$. For FVO, the osteotomy site at the intertrochanteric level was fixated using a blade plate (Stryker, Selzach, Switzerland) or a pediatric locking compression plate (Depuy Synthes, MA, USA). For Dega pelvic osteotomy, the osteotomy site was widened using a laminar spreader until sufficient coverage of the femoral head was achieved under $\mathrm{C}$-arm fluoroscopy. A tricortical iliac crest allograft was trimmed and inserted into the osteotomy site. Internal fixation of the bone graft was not performed. After surgery, bilateral short leg cast with an abduction bar were applied to maintain hip abduction position for 6 weeks. [20] Thereafter, all patients returned to a local rehabilitation center to begin standing and weight-bearing exercises.

\section{Consensus building}

A consensus building session was conducted for the selection of the radiographic parameters; this session included 5 orthopedic surgeons. Previous studies regarding graft incorporation after bone grafting were reviewed, and the Goldberg scoring system was selected. $[19,21]$ In hip radiographs, graft appearance, bony union at the proximal end and bony union at the distal end, were defined and evaluated. For graft appearance, the score was 0 for resorbed, 1 for mostly resorbed, 2 for largely intact, and 3 for reorganizing. For bony union at the proximal and distal ends, the score was 0 for nonunion, 1 for possible union, and 2 for complete union. [19] The highest possible score was 7 points, which indicated excellent graft reorganization and radiographic union (Fig. 1). For our study, radiographic delayed union was defined as a Goldberg score $<6$ by 6 months after the surgery.

Additionally, 3 radiographic parameters that were relevant to assessing hip displacement and acetabular dysplasia were selected from previous studies [3, 22-25]. These were the neck-shaft angle (NSA), MP, and acetabular index (AI) on hip radiographs (Fig. 2).

\section{Reliability testing and radiographic measurements}

To assess the inter-observer reliabilities of radiographic measurements, three orthopedic surgeons measured the radiographic indices including $\mathrm{MP}, \mathrm{NSA}, \mathrm{AI}$, and the Goldberg score for 36 hips independently. Four weeks after the inter-observer reliability testing, one orthopedic surgeon (JYK) performed the measurements again for 36 hips to evaluate the intra-observer reliability. After the completion of reliability test, he performed the measurement for all preoperative and postoperative follow-up hip radiographs.

\section{Statistical methods}

Inter- and intra-observer reliabilities of radiographic measurements were assessed by the ICCs and their 95\% CIs with the setting of a two-way mixed effects model, assuming a single measurement and absolute agreement. [26] Prior sample size estimation was performed for reliability testing with a target ICC value of 0.80 and a $95 \%$ $\mathrm{CI}$ width of 0.2 for 3 examiners. The minimum sample size was 36 hips, using Bonett's method. [27] An ICC value more than 0.8 represented excellent reliability. Repeated measures analysis of variance with a Bonferroni post hoc test was applied to compare the preoperative radiographic measurements to postoperative and final follow-up values.

Bilateral cases were included in this study, thus, a linear mixed model (LMM) and a generalized estimating equation (GEE) were used for statistical analysis. [28] The risk factors for radiographic delayed union were 


\section{Goldberg scoring system for pelvic bone graft}

\begin{tabular}{|l|l|l|l|}
\hline Index & \multicolumn{2}{|l|}{ Point } & Check \\
\hline 1. Graft appeareance & \multicolumn{2}{l|}{ Graft appearance } \\
\hline Resorbed & 0 & \\
Mostly resorbed & 1 & \\
Largely intact & 2 & \\
Reorganizing & 3 & \\
\hline 2. Bony union (Proximal) & \\
\hline Nonunion & 0 & \\
Possible union & 1 & \\
Radiographic union & 2 & \\
\hline 3. Bony union (Distal) & & \\
\hline Nonunion & 0 & \\
Possible union & 1 & \\
Radiographic union & 2 & \\
\hline Total & & \\
\hline
\end{tabular}

Fig. 1 Indices of the Goldberg scoring system are shown. A postoperative hip radiograph is used for the checklist. There was no case with scores 0 and 1 for graft appearance, and no case with score 0 for proximal and distal bony union. Modified from Goldberg VM, Powell A, Shaffer JW, Zika J, Bos GD, Heiple KG. Bone grafting: role of histocompatibility in transplantation. J Orthop Res. 1985;3:389-404. Copyright @ 1985 Orthopaedic Research Society

evaluated by a GEE to calculate the adjusted odds ratios (ORs). The annual change in the MP, NSA, and AI was adjusted by multiple factors by using a LMM. $\mathrm{R}$ version 3.2.5 (R Foundation for Statistical Computing, Vienna, Austria) and SAS 9.4.2 (SAS Institute, Cary, NC, USA) were used for statistical analysis, and $p$-values less than 0.05 were considered to be significant.

\section{Results}

One hundred ten patients with 150 hips were enrolled in this study. The mean number of follow-up radiographs was 6 per patients (range, 2-15) (Table 1).

Inter- and intra-observer reliabilities of all radiographic measurements were excellent (ICC, 0.802 to 0.924 ) (Table 2). MP, NSA and AI were significantly improved after hip reconstructive surgery including the Dega osteotomy (all $p<$ $0.001)$. AI was not changed at final follow-up $(p=1.000)$, but MP and NSA had significantly increased at final follow-up (both $p<0.001$ ) (Table 3).

The mean estimated Goldberg score was 6 at 1.1 years after Dega osteotomy (Fig. 3). Twenty-four hips $(16 \%, 4$ hips with GMFCS level IV and 20 hips with GMFCS level V) were classified as radiographic delayed union (Goldberg score $<6$ ) at 6 months after surgery. Nine hips (6\%, all hips with GMFCS level V) had Goldberg score $<6$ at 1 year after surgery. However, all hips showed radiographic union at the final follow-ups and no hips underwent reoperation due to nonunion. There were no cases of bone graft resorption, nonunion, dislodgement, and graft-related infections (Fig. 4).

GMFCS level was significantly associated with radiographic delayed union $(p=0.001)$. Patients with GMFCS level $\mathrm{V}$ had 6.9 times higher risks for radiographic delayed union than those with GMFCS level III and IV. Other factors such as age, sex, anatomical type and body side were not associated with radiographic delayed union (Table 4).

AI was not increased by follow-up duration ( 0.2 degrees per year; $p=0.316$ ). However, MP and NSA were significantly increased by follow-up duration $(2.5 \%, p<$ 0.001 and 2.5 degrees, $p<0.001$, respectively) (Table 5).

\section{Discussion}

To our knowledge, this is the largest study investigating outcomes after Dega osteotomy and the first study regarding the allograft behavior after Dega osteotomy in patients with CP. This study showed that a Dega pelvic osteotomy using an allograft could not only correct acetabular dysplasia, but also keep it stable over time. Therefore, an allograft can be a good option as the interposition material for Dega osteotomy if a femoral autograft is not available. Additionally, this study found that allograft incorporation in patients with GMFCS Level V 


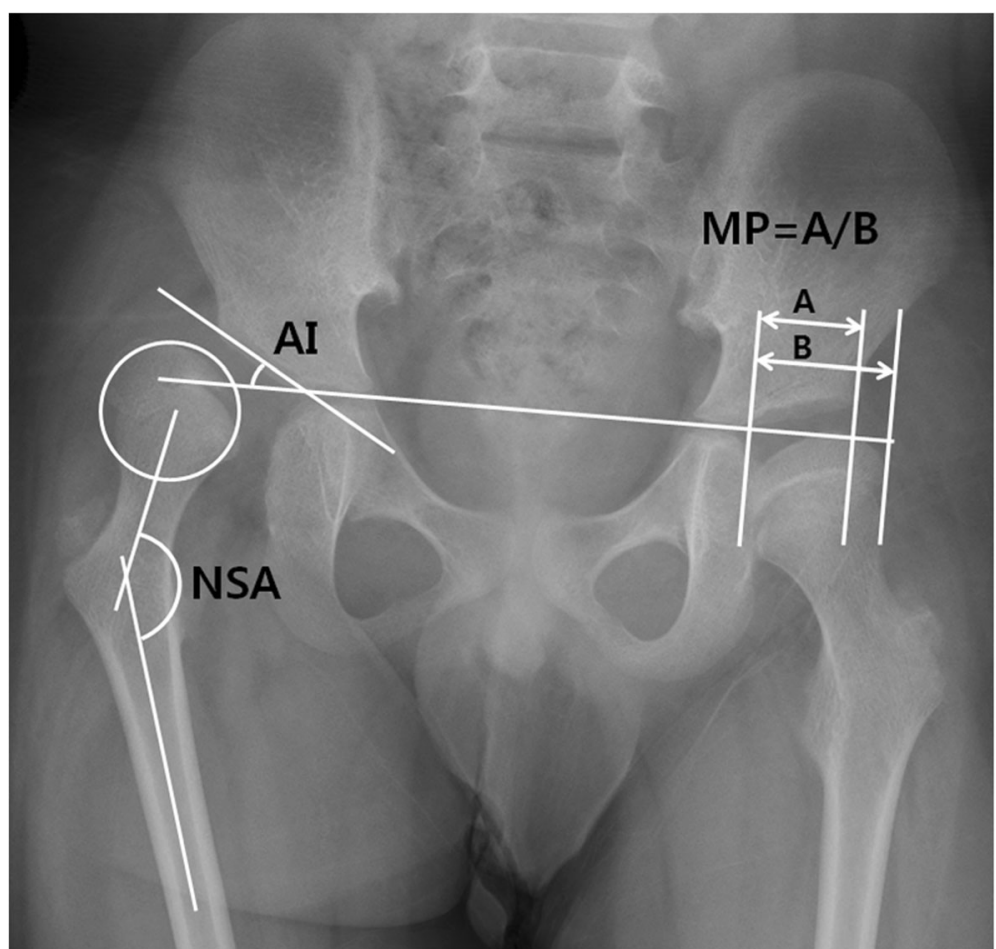

Fig. 2 Hip internal rotation view. For the right hip neck-shaft angle (NSA) was defined as the angle between a line passing through the center of the femoral shaft and another line connecting the center of the femoral head and the midpoint of the femoral neck. The center of the femoral head was the center of the largest best-fitting circle inside the femoral head. Acetabular index (Al) was defined as the angle between the acetabular roof and the Hilgenreiner's line. For the left hip, migration percentage (MP) was calculated by dividing the width of the femoral head lateral to Perkin's line (a) by the total width of the femoral head (b)

was significantly delayed compared to those with GMFCS level III and IV.

There were some limitations of this study. First, only retrospective review of medical records and radiographic assessments were used for evaluating surgical outcomes. However, we believe that allograft behavior can be reflected best by radiographic assessment. Second, all patients were not evaluated until skeletal maturity. However, all hips showed radiographic union at final follow-up without any allograft-related complication. Furthermore, our analysis showed that the correction of acetabular dysplasia remained stable throughout the follow-up duration. Therefore, we think that further

Table 1 Summary of patient data

\begin{tabular}{ll}
\hline Parameters & Values \\
\hline Male / Female & $68 / 42$ \\
Anatomical type (diplegia / guadriplegia) & $18 / 92$ \\
GMFCS level (III/IVN) & $17 / 39 / 54$ \\
Age at surgery (years) & $8.7 \pm 2.4$ (2.8 to 13.8) \\
Follow-up duration (years) & $2.9 \pm 2.6$ (1.0 to 12.0) \\
Age at final follow-up (years) & $11.6 \pm 3.8$ (3.8 to 22.5) \\
Laterality (Right / Left) & $80 / 70$
\end{tabular}

GMFCS Gross Motor Function Classification System follow-up may not be necessary. Thirds, no comparison group that used autograft for Dega osteotomy was included. Therefore, further study comparing the outcomes of allografts and autografts as graft materials for Dega osteotomy is required.

Most of authors used the iliac crest autograft or femoral autograft obtained from femoral shortening osteotomy as a bone graft material for Dega osteotomy and showed good clinical and radiological outcomes in patients with $\mathrm{CP}$ and developmental dysplasia of the hip (DDH) (Table 6). [6, 29-45] Mallet et al. investigated the long-term results after one-stage hip reconstructive surgery in children with CP. [37] They found that correction of AI remained

Table 2 Intra- and inter-observer reliabilities of radiographic measurements

\begin{tabular}{llllll}
\hline Measurements & \multicolumn{2}{l}{ Inter-observer reliability } & & \multicolumn{2}{l}{ Intra-observer reliability } \\
\cline { 2 - 3 } & ICC & $95 \% \mathrm{Cl}$ & & ICC & $95 \% \mathrm{Cl}$ \\
\hline Neck-shaft angle & 0.808 & $0.655-0.894$ & & 0.802 & $0.645-0.894$ \\
Migration percentage & 0.885 & $0.740-0.945$ & & 0.860 & $0.723-0.932$ \\
Acetabular index & 0.817 & $0.709-0.895$ & & 0.833 & $0.732-0.904$ \\
Goldberg score & 0.918 & $0.864-0.954$ & & 0.924 & $0.874-0.958$ \\
\hline
\end{tabular}

ICC intraclass correlation coefficient, $\mathrm{Cl}$ confidence interval 
Table 3 Summary of radiographic measurements

\begin{tabular}{lllllll}
\hline Radiographic index & Preoperative & $\begin{array}{l}\text { Immediate } \\
\text { postoperative }\end{array}$ & $\begin{array}{l}\text { Final } \\
\text { follow-up }\end{array}$ & P-value & \\
\cline { 5 - 7 } & & $13.6 \pm 5.5$ & $13.8 \pm 5.9$ & $<0.001$ & $<0.001$ & 1.000 \\
\hline Acetabular index (degree) & $32.2 \pm 7.0$ & $119.9 \pm 10.7$ & $125.1 \pm 13.6$ & $<0.001$ & $<0.001$ & $<0.001$ \\
Neck-shaft angle (degree) & $156.0 \pm 9.8$ & $0.5 \pm 2.3$ & $11.7 \pm 12.2$ & $<0.001$ & $<0.001$ & $<0.001$ \\
Migration percentage (\%) & $75.2 \pm 20.2$ & &
\end{tabular}

stable postoperatively for 9 years of follow-up. Jozwiak et al. also reported that AI did not show any noticeable changes during the follow-up period after Dega pelvic osteotomy in patients with CP. [31] Our study also showed that AI did not increase during the follow-up period.

On the contrary, previous studies have found that both NSA and MP showed a tendency to worsen during the follow-up period after hip reconstruction, including Dega osteotomy, in CP . [31, 37] In addition, Bayusentono et al. showed that MP significantly increased by $2.0 \%$ per year in patients with GMFCS level IV and by $3.5 \%$ per year in those with GMFCS level V. [24] Our study also showed that MP and NSA were significantly increased during the follow-up period, as reported in previous studies.

Several studies showed good surgical outcome after pelvic osteotomy using allograft for DDH patients. Wade et al. investigated the radiologic results of 147 hips treated for DDH by Dega osteotomy with an iliac crest allograft. [6] They showed that postoperative corrected AI had improved at 2 years of follow-up. McCarthy et al. compared the results of autograft and allograft in 36 hips after Pemberton osteotomy. [46] Almost all of the children with DDH had satisfactory results regardless of graft type, but allograft provided better results than iliac crest autograft in neuromuscular diseases. Kessler et al. also reported that allograft bone could be effectively used in Pemberton osteotomy in 26 hips with DDH or neuromuscular disorders. [47] The authors believed that the immediate stability, owing to the larger size and the mechanical properties of the graft, allowed for earlier rehabilitation.

Patients with CP have low BMD, which is highly correlated with GMFCS levels. Several factors, including physical disability, poor nutritional status, decreased calcium intake, low vitamin D level, prolonged immobilization, sarcopenia, and the use of anticonvulsant, were associated with the low BMD in patients with CP. [48-50] Moon et al. showed that bone attenuation of the acetabulum and femur neck was significantly

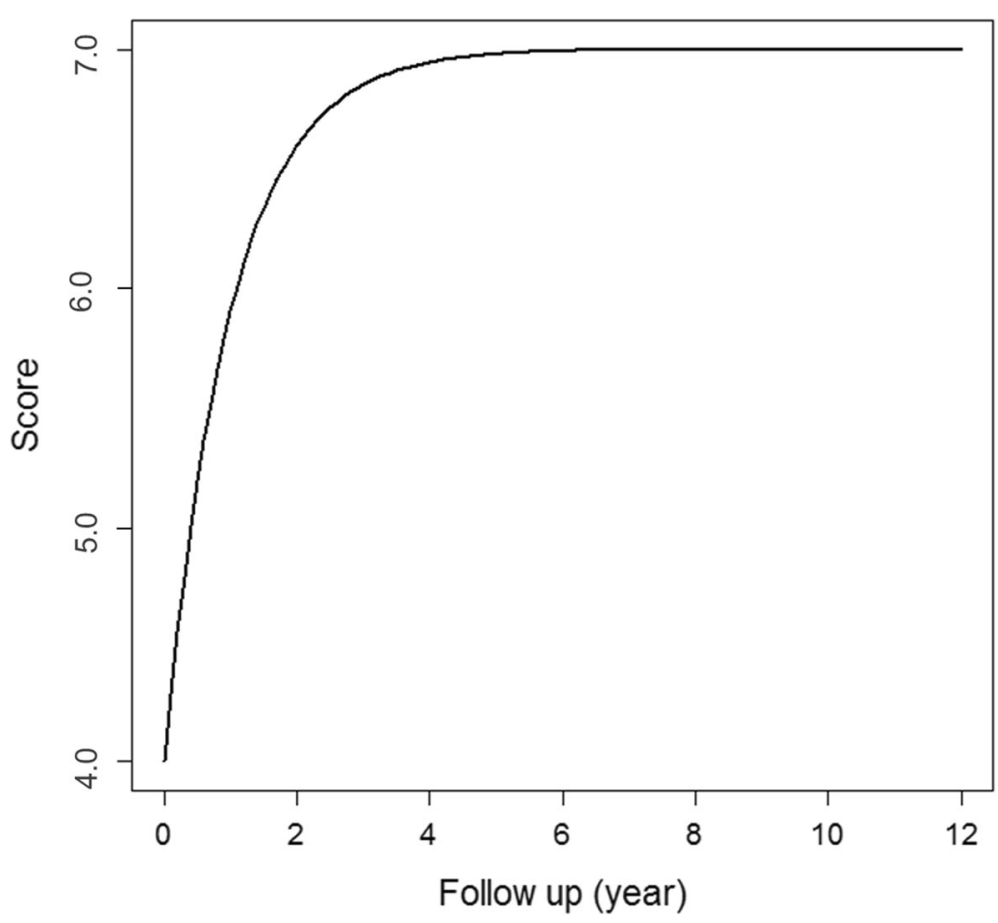

Fig. 3 Graph showing the mean Goldberg score according to the duration of follow-up after Dega osteotomy 


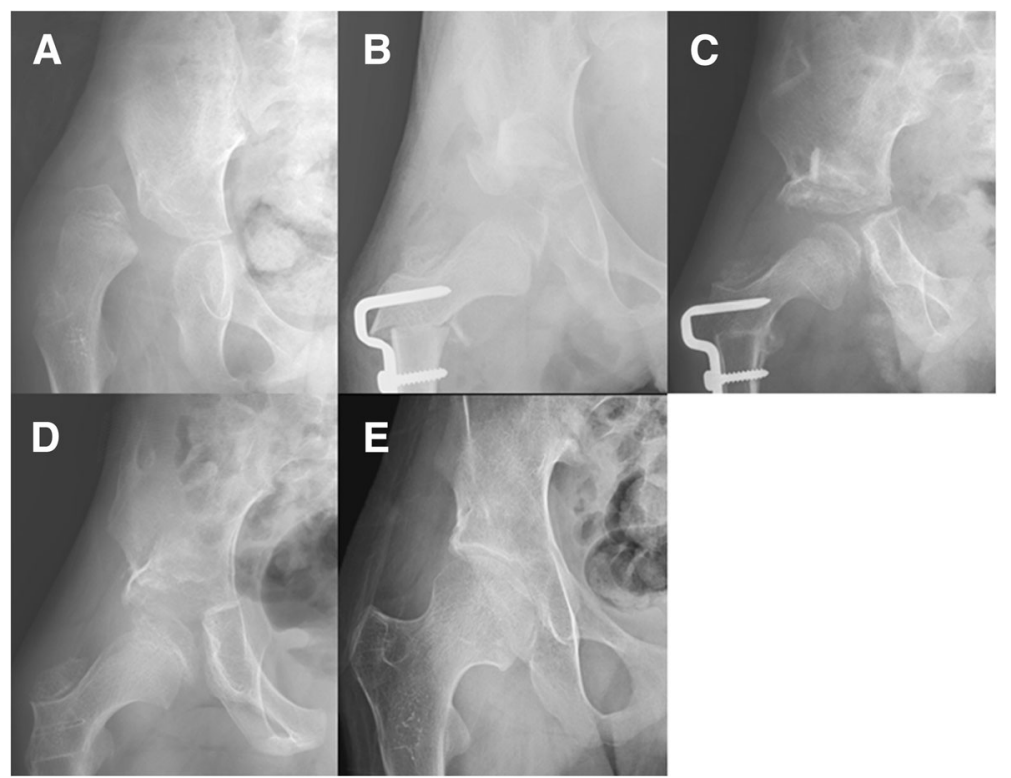

Fig. 4 a Preoperative hip radiograph of a 9-year-old body with cerebral palsy shows right hip dislocation and aceteabular dysplasia. b He underwent hip reconstructive surgery including Dega osteotomy using iliac crest allograft for right hip. c The osteotomy site was not incorporated yet at 6 months after the surgery (Goldberg score of 5), $\mathbf{d}$ It was completely incorporated at 1 year after the surgery (Goldberg score of 7). e Correction of acetabular dysplasia remained stable at 10 years after the surgery

affected by GMFCS levels and degree of hip displacement. [7] Because the osteoporotic features around hip joints in CP may not guarantee the initial mechanical stability of osteotomy site, we had used iliac crest allograft as the interposition material at the osteotomy site.

Allograft has been proven to be a good choice of graft in other pediatric orthopedic conditions. Wade et al. showed that all of the allografts were completely incorporated at 6 months after surgery with a mean incorporation time of 3 months in 147 hips treated for DDH by Dega osteotomy. [6] Lee et al. investigated the incidence and risk factors of allograft failure after lateral column lengthening for planovalgus foot deformity. [19] They reported that the mean estimated Goldberg score was 6 at 6 months after surgery and $4 \%$ of feet had Goldberg score $<6$ at 6 months after surgery. Additionally, reoperation using an autogenous iliac bone graft bone was performed in four feet (1\%). In our study, the mean

Table 4 Potential risk factors for radiographic delayed union

\begin{tabular}{lll}
\hline Factor & Adjusted OR (95\% Cl) & $P$-value \\
\hline Age (per year) & $0.9(0.8$ to 1.1$)$ & 0.443 \\
Sex (male) & $0.4(0.2$ to 1.0$)$ & 0.062 \\
GMFCS level $(V)$ & $6.9(2.2$ to 22.2$)$ & 0.001 \\
Anatomical type (quadriplegia) & $2.3(0.2$ to 22.5$)$ & 0.476 \\
Body side (right) & $1.6(0.6$ to 4.0$)$ & 0.365 \\
\hline
\end{tabular}

OR odds ratio, $C l$ confidence interval, GMFCS Gross Motor Function Classification System; Multivariate analysis using generalized estimation equation is used to calculate the $\mathrm{OR}$ and $\mathrm{Cl}$ estimated Goldberg score was 6 at 1.1 years after Dega osteotomy and at 6 months after the surgeries, $16 \%$ of hips had a Goldberg score of $<6$. Furthermore, allograft incorporation in patients with GMFCS Level V was significantly delayed than in those with GMFCS level III and IV. However, no hip underwent reoperation due to allograft failure. We think that the delayed allograft incorporation in our study, compared with previous studies, is due to the underlying $\mathrm{CP}$ in the included patients with GMFCS level III to V. On the other hand, Wade et al.'s study included patients with DDH, and Lee et al's study included patients with idiopathic planovalgus and ambulatory CP. We think that the delayed allograft incorporation in patients with GMFCS level V compared with those with GMFCS level III and IV is due to the severity of osteoporosis. Therefore, surgeons should remember that the degree of osteoporosis might affect the time to allograft incorporation and pay extra attention to the patients with GMFCS level V.

\section{Conclusion}

Dega pelvic osteotomy using iliac crest allograft was an effective procedure in the correction of acetabular dysplasia without graft-related complications in patients with CP. Additionally, the correction of acetabular dysplasia remained stable during the follow-up period. However, physicians should consider that allograft incorporation in patients with GMFCS level V can be delayed compared with those with GMFCS level III \& IV. 
Table 5 Factors affecting radiographic measurements after hip reconstructive surgery

\begin{tabular}{|c|c|c|c|c|c|c|c|c|c|}
\hline & \multicolumn{3}{|c|}{ Acetabula index } & \multicolumn{3}{|c|}{ Migration percentage } & \multicolumn{3}{|c|}{ Neck-shaft angle } \\
\hline & Estimate & SE & $\overline{P \text {-value }}$ & Estimate & SE & $P$-value & Estimate & SE & $P$-value \\
\hline Follow-up duration (year) & 0.2 & 0.2 & 0.316 & 2.5 & 0.2 & $<0.001$ & 2.5 & 0.3 & $<0.001$ \\
\hline Age at surgery & -0.0 & 0.2 & 0.919 & 0.2 & 0.2 & 0.349 & -1.3 & 0.3 & $<0.001$ \\
\hline Sex & 0.0 & 0.8 & 0.961 & -2.3 & 1.1 & 0.036 & 2.5 & 1.7 & 0.127 \\
\hline \multicolumn{10}{|l|}{ GMFCS level } \\
\hline \multicolumn{10}{|l|}{ V (reference) } \\
\hline III & 3.1 & 1.2 & 0.010 & 3.8 & 1.5 & 0.013 & 9.1 & 2.4 & $<0.001$ \\
\hline IV & 1.2 & 0.9 & 0.198 & 0.6 & 1.2 & 0.600 & 3.1 & 1.8 & 0.086 \\
\hline Anatomical type & -0.2 & 1.2 & 0.873 & -0.1 & 2.0 & 0.966 & -2.2 & 2.8 & 0.445 \\
\hline Laterality & -1.1 & 0.8 & 0.001 & -0.1 & 1.0 & 0.451 & -1.2 & 1.6 & 0.835 \\
\hline
\end{tabular}

A linear mixed model was used to estimate factors affecting Al, MP and NSA

SE standard error, GMFCS Gross Motor Function Classification System

Table 6 Previous studies on the outcome after Dega osteotomy

\begin{tabular}{|c|c|c|c|c|c|c|c|c|c|c|c|c|c|c|}
\hline \multirow[t]{2}{*}{ Author } & \multirow[t]{2}{*}{ Diagnosis } & \multirow[t]{2}{*}{ Graft material } & \multirow{2}{*}{$\begin{array}{l}\text { No. } \\
\text { of } \\
\text { hips }\end{array}$} & \multirow{2}{*}{$\begin{array}{l}\text { Age at } \\
\text { surgery } \\
\text { (year) }\end{array}$} & \multirow{2}{*}{$\begin{array}{l}\text { Follow- } \\
\text { up } \\
\text { duration } \\
\text { (year) }\end{array}$} & \multicolumn{3}{|l|}{$\mathrm{Al}\left({ }^{\circ}\right)$} & \multicolumn{3}{|c|}{ MP (\%) } & \multicolumn{3}{|l|}{ NSA $\left(^{\circ}\right)$} \\
\hline & & & & & & Preop & Postop & final & Preop & Postop & final & Preop & Postop & final \\
\hline $\begin{array}{l}\text { Current } \\
\text { study }\end{array}$ & $C P$ & Iliac crest allograft & 150 & 8.7 & 2.9 & 32.2 & 13.6 & 13.8 & 75.2 & 0.5 & 11.7 & 156 & 119.9 & 125.1 \\
\hline $\begin{array}{l}\text { Mubarak } \\
\text { [29] }\end{array}$ & $\mathrm{CP}$ & Iliac crest autograft & 18 & 8.4 & 6.8 & 30 & & 14 & 78 & & 6.2 & 149 & & 95 \\
\hline $\begin{array}{l}\text { McNerney } \\
{[30]}\end{array}$ & $\mathrm{CP}$ & Iliac crest autograft & 104 & 8.1 & 6.9 & 26 & 13 & 11 & 66 & 5 & 14 & & & \\
\hline $\begin{array}{l}\text { Jozwiak } \\
\text { [31] }\end{array}$ & $\mathrm{CP}$ & & 30 & 7.0 & 12.0 & 32 & 22 & 23 & 65 & 11 & 20 & 152 & 133 & 140 \\
\hline Robb [32] & $\mathrm{CP}$ & Femoral autograft & 52 & 14.0 & 4.0 & & & & 70 & 10 & & & & \\
\hline Kim [33] & $C P$ & Iliac crest or femoral autograft & 32 & 8.6 & 2.3 & 35.7 & 19 & & 74.2 & 10.6 & & & & \\
\hline $\begin{array}{l}\text { Dhawale } \\
\text { [34] }\end{array}$ & $C P$ & & 22 & 7.5 & 11.7 & & & & 79.4 & 4.3 & 7.9 & 151 & 112 & 120.6 \\
\hline Koch [35] & $\mathrm{CP}$ & Femoral autograft & 115 & 9.0 & 5.5 & 30.7 & 21.3 & & 98.3 & 16 & & 142 & 119.6 & 119.3 \\
\hline Braatz [36] & $C P$ & Femoral autograft & & 7.3 & 7.7 & & & & 68 & 12 & 16 & & & \\
\hline Mallet [37] & $\mathrm{CP}$ & Femoral autograft & 20 & 8.1 & 9.1 & 30.1 & 12.7 & 15.8 & 60.6 & 4.9 & 15.4 & 153 & 114.6 & 129.7 \\
\hline Reidy [38] & $\mathrm{CP}$ & Femoral autograft & 57 & 8.9 & 5.4 & & & & 63.6 & 2.7 & 9.7 & 152 & 132.6 & 137.2 \\
\hline $\begin{array}{l}\text { Grudziak } \\
\text { [39] }\end{array}$ & $\mathrm{DDH}$ & $\begin{array}{l}\text { lliac crest or femoral autograft } \\
\text { or fibular allograft }\end{array}$ & 24 & 5.8 & 4.6 & 33 & 12 & & & & & & & \\
\hline \multirow[t]{2}{*}{ Karlen [40] } & $\mathrm{DDH}$ & Iliac crest or femoral autograft & 26 & 3.1 & 4.3 & 37 & 15 & 13 & & & & & & \\
\hline & NM & & 24 & 6.3 & 4.7 & 36 & 16 & 14 & 84 & 8 & 14 & & & \\
\hline Wade [6] & $\mathrm{DDH}$ & Iliac crest allograft & 147 & 2.9 & 2.0 & 43.2 & 24.3 & 16.9 & & & & & & \\
\hline $\begin{array}{l}\text { Al-Ghamdi } \\
\text { [41] }\end{array}$ & $\mathrm{DDH}$ & & 21 & 4.6 & 7.3 & 37 & 17 & 19 & 38 & -10 & 15 & & & \\
\hline Aksoy [42] & $\mathrm{DDH}$ & Iliac crest or femoral autograft & 43 & 2.9 & 4.8 & 35 & 20 & 13 & & & & & & \\
\hline Akgul [43] & $\mathrm{DDH}$ & & 26 & 3.2 & 3.5 & 39.4 & 18.3 & 15 & & & & & & \\
\hline $\begin{array}{l}\text { El-Sayed } \\
{[44]}\end{array}$ & $\mathrm{DDH}$ & Iliac crest or femoral autograft & 58 & 4.1 & 16.6 & 39 & 18 & 25 & & -21 & 19 & & & \\
\hline Issin [45] & $\mathrm{DDH}$ & Iliac crest autograft & 10 & 2.1 & 5.6 & 46 & 23.4 & 15.9 & & & & & & \\
\hline
\end{tabular}




\section{Abbreviations}

Al: Acetabular index; CP: Cerebral palsy; DDH: Developmental dysplasia of hip; FVO: Femoral varization osteotomy; GEE: Generalized estimating equation; GMFCS: Gross Motor Function Classification System; LMM: Linear mixed model; MP: Migration percentage; NSA: Neck-shaft angle

\section{Acknowledgements}

The authors thank Seung Joon Moon, MD and Arif Zulkarnain, MD for reliability measurements.

\section{Funding}

This research was supported by Korea Institute of Planning and Evaluation for Technology in Food, Agriculture, Forestry and Fisheries(IPET) throughHigh Value-added Food Technology Development Program, funded by Ministry of Agriculture, Food and Rural Affairs(MAFRA)(117051-3), by Ministry of SMEs and Startups (grant no. S2409723), and the SNUBH Research Fund (grant no. 03-2013-005).

\section{Availability of data and materials}

The data set supporting the conclusion of this article is available on request to the corresponding author.

\section{Authors' contributions}

All authors on this manuscript (KHS, SSK, CYC, KML, JK and MSP) made significant contributions to the study design. KHS, SSK, and JK were involved in acquisition of data. KHS, SSK, KML, JK and MSP were involved in the analysis and interpretation of data, as well as drafting the manuscript. All authors gave final approval of the version to be published.

\section{Ethics approval and consent to participate}

This study was approved by the institutional review board of Seoul National University Bundang Hospital (IRB number: B-1704/391-102), which waived informed consent because of its retrospective design.

\section{Consent for publication}

Not applicable

\section{Competing interests}

The authors declare that they have no competing interests.

\section{Publisher's Note}

Springer Nature remains neutral with regard to jurisdictional claims in published maps and institutional affiliations.

\section{Author details}

'Department of Orthopaedic Surgery, Seoul National University Bundang Hospital, 82 Gumi-ro 173 Beon-gil, Bundang-Gu, Sungnam, Gyeonggi 13620 South Korea. ${ }^{2}$ Department of Mathematics, College of Natural Sciences, Ajou University, Suwon, Gyeonggi, South Korea. ${ }^{3}$ Department of Orthopaedic Surgery, H Plus Yangji Hospital, Seoul, South Korea.

Received: 8 April 2018 Accepted: 3 October 2018 Published online: 16 October 2018

\section{References}

1. Bax M, Goldstein M, Rosenbaum P, Leviton A, Paneth N, Dan B, Jacobsson B, Damiano D. Executive Committee for the Definition of Cerebral P: Proposed definition and classification of cerebral palsy, April 2005. Dev Med Child Neurol. 2005;47:571-6.

2. Scrutton D, Baird G, Smeeton N. Hip dysplasia in bilateral cerebral palsy: incidence and natural history in children aged 18 months to 5 years. Dev Med Child Neurol. 2001:43:586-600

3. Hagglund G, Lauge-Pedersen $H$, Wagner P. Characteristics of children with hip displacement in cerebral palsy. BMC Musculoskelet Disord. 2007:8:101.

4. Hoffer MM, Stein GA, Koffman M, Prietto M. Femoral varus-derotation osteotomy in spastic cerebral palsy. J Bone Joint Surg Am. 1985;67:1229-35.

5. Dega W. Transiliac osteotomy in the treatment of congenital hip dysplasia. Chir Narzadow Ruchu Ortop Pol. 1974;39:601-13.

6. Wade WJ, Alhussainan TS, Al Zayed Z, Hamdi N, Bubshait D. Contoured iliac crest allograft interposition for pericapsular acetabuloplasty in developmental dislocation of the hip: technique and short-term results. J Child Orthop. 2010:4:429-38.

7. Moon SY, Kwon SS, Cho BC, Chung CY, Lee KM, Sung KH, Chung MK, Zulkarnain A, Kim YS, Park MS. Osteopenic features of the hip joint in patients with cerebral palsy: a hospital-based study. Dev Med Child Neurol. 2016;58:1153-8.

8. Rossillon R, Desmette D, Rombouts JJ. Growth disturbance of the ilium after splitting the iliac apophysis and iliac crest bone harvesting in children: a retrospective study at the end of growth following unilateral Salter innominate osteotomy in 21 children. Acta Orthop Belg. 1999;65:295-301.

9. Goulet JA, Senunas LE, DeSilva GL, Greenfield ML. Autogenous iliac crest bone graft. Complications and functional assessment. Clin Orthop Relat Res. 1997;339:76-81.

10. Mahan KT, Hillstrom HJ. Bone grafting in foot and ankle surgery. A review of 300 cases. J Am Podiatr Med Assoc. 1998;88:109-18.

11. Dolan CM, Henning JA, Anderson JG, Bohay DR, Kornmesser MJ, Endres TJ. Randomized prospective study comparing tri-cortical iliac crest autograft to allograft in the lateral column lengthening component for operative correction of adult acquired flatfoot deformity. Foot Ankle Int. 2007;28:8-12.

12. Bauer TW, Muschler GF. Bone graft materials. An overview of the basic science. Clin Orthop Relat Res. 2000;371:10-27.

13. Cypher TJ, Grossman JP. Biological principles of bone graft healing. J Foot Ankle Surg. 1996;35:413-7

14. Scarborough NL, White EM, Hughes JV, Manrique AJ, Poser JW. Allograft safety: viral inactivation with bone demineralization. Contemp Orthop. 1995;31:257-61

15. Ehrler DM, Vaccaro AR. The use of allograft bone in lumbar spine surgery. Clin Orthop Relat Res. 2000;371:38-45.

16. Nugent PJ, Dawson EG. Intertransverse process lumbar arthrodesis with allogeneic fresh-frozen bone graft. Clin Orthop Relat Res. 1993;287:107-11.

17. Segur JM, Torner P, Garcia S, Combalia A, Suso S, Ramon R. Use of bone allograft in tibial plateu fractures. Arch Orthop Trauma Surg. 1998;117:357-9.

18. Tomford WW. Bone allografts: past, present and future. Cell Tissue Bank. 2000;1:105-9.

19. Lee $\mathrm{H}$, Chung CY, Lee KM, Kwon SS, Moon SY, Jung KJ, Chung MK, Park MS Incidence and risk factors of allograft bone failure after calcaneal lengthening. Clin Orthop Relat Res. 2015;473:1765-74.

20. Sung KH, Kwon SS, Chung CY, Lee KM, Kim J, Lee SY, Park MS. Fate of stable hips after prophylactic femoral varization osteotomy in patients with cerebral palsy. BMC Musculoskelet Disord. 2018;19:130.

21. Goldberg VM, Powell A, Shaffer JW, Zika J, Bos GD, Heiple KG. Bone grafting: role of histocompatibility in transplantation. J Orthop Res. 1985;3:389-404.

22. Gordon GS, Simkiss DE. A systematic review of the evidence for hip surveillance in children with cerebral palsy. J Bone Joint Surg Br. 2006;88:1492-6.

23. Park JY, Choi Y, Cho BC, Moon SY, Chung CY, Lee KM, Sung KH, Kwon SS, Park MS. Progression of Hip Displacement during Radiographic Surveillance in Patients with Cerebral Palsy. J Korean Med Sci. 2016;31:1143-9.

24. Bayusentono S, Choi Y, Chung CY, Kwon SS, Lee KM, Park MS. Recurrence of hip instability after reconstructive surgery in patients with cerebral palsy. J Bone Joint Surg Am. 2014;96:1527-34.

25. Pidcock FS, Fish DE, Johnson-Greene D, Borras I, McGready J, Silberstein CE. Hip migration percentage in children with cerebral palsy treated with botulinum toxin type A. Arch Phys Med Rehabil. 2005:86:431-5.

26. Lee KM, Lee J, Chung CY, Ahn S, Sung KH, Kim TW, Lee HJ, Park MS. Pitfalls and important issues in testing reliability using intraclass correlation coefficients in orthopaedic research. Clin Orthop Surg. 2012;4:149-55.

27. Bonett DG. Sample size requirements for estimating intraclass correlations with desired precision. Stat Med. 2002;21:1331-5.

28. Park MS, Kim SJ, Chung CY, Choi $\|_{\text {, Lee } S H}$, Lee KM. Statistical consideration for bilateral cases in orthopaedic research. J Bone Joint Surg Am. 2010;92:1732-7.

29. Mubarak SJ, Valencia FG, Wenger DR. One-stage correction of the spastic dislocated hip. Use of pericapsular acetabuloplasty to improve coverage. J Bone Joint Surg Am. 1992;74:1347-57.

30. McNerney NP, Mubarak SJ, Wenger DR. One-stage correction of the dysplastic hip in cerebral palsy with the San Diego acetabuloplasty: results and complications in 104 hips. J Pediatr Orthop. 2000:20:93-103.

31. Jozwiak M, Koch A. Two-stage surgery in the treatment of spastic hip dislocation--comparison between early and late results of open reduction and derotation-varus femoral osteotomy combined with Dega pelvic osteotomy preceded by soft tissue release. Ortop Traumatol Rehabil. 2011:13:144-54.

32. Robb JE, Brunner R. A Dega-type osteotomy after closure of the triradiate cartilage in non-walking patients with severe cerebral palsy. J Bone Joint Surg Br. 2006;88:933-7. 
33. Kim HT, Jang JH, Ahn JM, Lee JS, Kang DJ. Early results of one-stage correction for hip instability in cerebral palsy. Clin Orthop Surg. 2012;4:139-48.

34. Dhawale AA, Karatas AF, Holmes L, Rogers KJ, Dabney KW, Miller F. Longterm outcome of reconstruction of the hip in young children with cerebral palsy. Bone Joint J. 2013;95-B:259-65.

35. Koch A, Jozwiak M, Idzior M, Molinska-Glura M, Szulc A. Avascular necrosis as a complication of the treatment of dislocation of the hip in children with cerebral palsy. Bone Joint J. 2015;97-B:270-6.

36. Braatz F, Staude D, Klotz MC, Wolf SI, Dreher T, Lakemeier S. Hip-joint congruity after Dega osteotomy in patients with cerebral palsy: long-term results. Int Orthop. 2016:40:1663-8.

37. Mallet C, llharreborde B, Presedo A, Khairouni A, Mazda K, Pennecot GF. One-stage hip reconstruction in children with cerebral palsy: long-term results at skeletal maturity. J Child Orthop. 2014;8:221-8.

38. Reidy K, Heidt C, Dierauer S, Huber H. A balanced approach for stable hips in children with cerebral palsy: a combination of moderate VDRO and pelvic osteotomy. J Child Orthop. 2016;10:281-8.

39. Grudziak JS, Ward WT. Dega osteotomy for the treatment of congenital dysplasia of the hip. J Bone Joint Surg Am. 2001;83-A:845-54.

40. Karlen JW, Skaggs DL, Ramachandran M, Kay RM. The Dega osteotomy: a versatile osteotomy in the treatment of developmental and neuromuscular hip pathology. J Pediatr Orthop. 2009;29:676-82.

41. Al-Ghamdi A, Rendon JS, Al-Faya F, Saran N, Benaroch T, Hamdy RC. Dega osteotomy for the correction of acetabular dysplasia of the hip: a radiographic review of 21 cases. J Pediatr Orthop. 2012;32:113-20.

42. Aksoy C, Yilgor C, Demirkiran G, Caglar O. Evaluation of acetabular development after Dega acetabuloplasty in developmental dysplasia of the hip. J Pediatr Orthop B. 2013;22:91-5.

43. Akgul T, Bora Goksan S, Bilgili F, Valiyev N, Hurmeydan OM. Radiological results of modified Dega osteotomy in Tonnis grade 3 and 4 developmental dysplasia of the hip. J Pediatr Orthop B. 2014;23:333-8.

44. El-Sayed MM, Hegazy M, Abdelatif NM, ElGebeily MA, ElSobky T, Nader S Dega osteotomy for the management of developmental dysplasia of the hip in children aged 2-8 years: results of 58 consecutive osteotomies after 13-25 years of follow-up. J Child Orthop. 2015;9:191-8.

45. Issin A, Oner A, Kockara N, Camurcu Y. Comparison of open reduction alone and open reduction plus Dega osteotomy in developmental dysplasia of the hip. J Pediatr Orthop B. 2016;25:1-6.

46. McCarthy JJ, Palma DA, Betz RR. Comparison of autograft and allograft fixation in Pemberton osteotomy. Orthopedics. 2008;31:126.

47. Kessler Jl, Stevens PM, Smith JT, Carroll KL. Use of allografts in Pemberton osteotomies. J Pediatr Orthop. 2001;21:468-73.

48. Henderson RC, Lark RK, Gurka MJ, Worley G, Fung EB, Conaway M, Stallings VA, Stevenson RD. Bone density and metabolism in children and adolescents with moderate to severe cerebral palsy. Pediatrics. 2002;110:e5.

49. Tatay Diaz A, Farrington DM, Downey Carmona FJ, Macias Moreno ME, Quintana del Olmo JJ. Bone mineral density in a population with severe infantile cerebral palsy. Rev Esp Cir Ortop Traumatol. 2012;56:306-12.

50. Houlihan CM, Stevenson RD. Bone density in cerebral palsy. Phys Med Rehabil Clin N Am. 2009:20:493-508.

Ready to submit your research? Choose BMC and benefit from:

- fast, convenient online submission

- thorough peer review by experienced researchers in your field

- rapid publication on acceptance

- support for research data, including large and complex data types

- gold Open Access which fosters wider collaboration and increased citations

- maximum visibility for your research: over $100 \mathrm{M}$ website views per year

At $\mathrm{BMC}$, research is always in progress.

Learn more biomedcentral.com/submissions 